Penultimate version, forthcoming in Synthese

\title{
The Value of Truth and the Normativity of Evidence ${ }^{1}$
}

\author{
Tommaso Piazza \\ (University of Pavia)
}

To say that evidence is normative is to say that what evidence one possesses, and how this evidence relates to any proposition, determines which attitude among believing, disbelieving and withholding one ought to take toward this proposition if one deliberates about whether to believe it. It has been suggested by McHugh that this view can be vindicated by resting on the premise that truth is epistemically valuable. In this paper, I modify the strategy sketched by McHugh so as to overcome the initial difficulty that it is unable to vindicate the claim that on counterbalanced evidence with respect to $P$ one ought to conclude deliberation by withholding on $P$. However, I describe the more serious difficulty that this strategy rests on principles whose acceptance commits one to acknowledging non-evidential reasons for believing. A way to overcome this second difficulty, against the evidentialists who deny this, is to show that we sometimes manage to believe on the basis of non-epistemic considerations. If this is so, one fundamental motivation behind the evidentialist idea that non-epistemic considerations could not enter as reasons in deliberation would lose its force. In the second part of this paper I address several strategies proposed in the attempt to show that we sometimes manage to believe on the basis of non-epistemic considerations and show that they all fail. So, I conclude that the strategy inspired by McHugh to ground the normativity of evidence of the value of truth ultimately fails.

\section{Introduction}

It is widely held that truth is an intrinsic epistemic value. To say so is not to deny that truth might also be of general instrumental value, as a means to achieving one's practical goals. Having true beliefs, it seems sensible to suggest, is instrumentally valuable precisely for this reason. But to say that truth is of intrinsic epistemic value is to say that the part of its goodness that is distinctively epistemic is not derivative on some other epistemic value to

\footnotetext{
${ }^{1} \mathrm{I}$ am extremely grateful to two anonymous referees of this journal for their insightful and helpful comments.
} 
which truth is a reliable means. In addition, it can be maintained that truth is the sole, or the most fundamental, epistemic value (see for instance Pritchard $2011,2014,{ }^{2}$ or, for a recent example, Sylvan 2018). With this, it is meant that any other epistemic good-like for instance justification, reliability and the like-derives its value from the fact that it is a means to realizing the value of truth. This latter claim is more controversial, and I will stay neutral with respect to it. ${ }^{3}$ However, I will take for granted the weaker claim that truth is at least one among a variety of intrinsic epistemic values. What I want to address is the question about whether the claim that truth is valuable in this sense may help us to better understand a different epistemic phenomenon, that I will call the normativity of evidence. In the sense I will assume for the purpose of this paper, a subject $S$ has evidence that a given proposition is true just in case $S$ is aware of an indication of P's truth. To say that evidence is normative is to say, roughly, that given any proposition $\mathrm{P}$, what evidence one has, and how this evidence relates to $P$, determines what doxastic attitude one ought to take toward $\mathrm{P}$ if one deliberates about whether to believe it. ${ }^{4}$ The question that I shall

\footnotetext{
${ }^{2}$ But also see Pritchard 2009, and 2010 for a defense of the different view that knowledge and understanding are fundamental epistemic values.

${ }^{3}$ See Matheson (2011) for an explicit recent defense of epistemic value pluralism. One well-known difficulty with the claim that truth is the sole epistemic value is that it is prima facie incompatible with the independently plausible claim that knowledge is more valuable than true belief. This problem for truth value monism is known as the Swamping Problem (see Kvanvig 2003; Zagzebski 2000, 2003). Very roughly, the problem is this. Suppose truth is the sole intrinsic epistemic good, and that any other epistemic good is instrumentally valuable just as a means to truth. It seems independently plausible that the presence of something that is instrumentally valuable as a means to an intrinsic good cannot increase the value of something that already possesses that intrinsic good. Since knowledge is true belief accompanied by some other epistemic valuable thing (e.g. justification, reliability etc.), it seems to follow from the premise that any other epistemic good is instrumentally valuable just as a means to truth that knowledge could not be more valuable than true belief. See Pritchard (2011), Sylvan (2018) and Pettigrew (forthcoming) for an attempt to solve the swamping problem for truth value monism.

${ }^{4}$ One possible difficulty for the view that evidence is normative in this sense derives from the psychological observation that we do not exert direct voluntary control over whether to believe (see Alston 1987, and Feldman 2000). In this paper I won't address this possible difficulty and will just be concerned with the question about whether the normativity of evidence can be grounded on the value of truth. It deserves emphasis, however, that the debate about doxastic voluntarism will be indirectly relevant to my topic. On one reading of it, Williams (1973)'s influential argument for the contention that doxastic voluntarism is necessarily false is premised on the claim that we cannot believe on the basis on non-epistemic considerations. This claim will be relevant for what follows, as it will be relevant to whether non-epistemic considerations counting in favor of having a belief can be regarded as reasons for believing.
} 
explore is whether the view that evidence is normative in this sense can be vindicated by relying on the claim that truth is of an intrinsic epistemic value.

C. McHugh (2012: 21) has alluded at an interesting strategy to support an affirmative answer to this question based on a general principle connecting values and reasons/norms. In accordance with this principle, very roughly, if $\mathrm{R}$ is a reason for taking it that a course of action $X$ is conducive to the realization of a good thing, $R$ is a reason to do $\mathrm{X}$.

My first aim in this paper is corrective and is to amend McHugh's strategy. As it stands, this strategy is not sufficient to vindicate the claim that on counterbalanced evidence in relation to $\mathrm{P}$ one should withhold on $\mathrm{P}$. This first problem can however be circumvented by invoking a different principle connecting (negative) values and reasons/norms. According to this principle, if one has no reason to rule it out that by doing $X$ one would bring about something bad, one has a reason to refrain from doing $X$.

My second aim is more negative and is to show that the second amended strategy to ground the normativity of evidence on the value of truth, as well as McHugh's original strategy, is faced with a more serious difficulty. In recent times, many philosophers have contended that epistemic reasons are the sole reasons for believing there are (Kelly 2002, Shah 2006, Parfit 2011, Way 2016, Berker 2018). These evidentialist philosophers have argued that epistemic reasons are the sole reasons for believing there are by elaborating on Williams (1973)'s classical theme that one cannot believe at will, namely on the basis of non-epistemic considerations counting in favor of having a given belief. This fact, according to the authors at issue, indicates that these considerations are not reasons for believing, because they cannot play a role in deliberation. The problem with the strategy above to vindicate the normativity of evidence is that it relies on principles-those connecting values to reasons/norms - that commit to acknowledging non-epistemic as well as epistemic reasons for believing. 
One popular strategy to undercut the claim that evidential reasons are the sole reasons for believing there are is to point to cases in which a subject is alleged to believe on the basis of non-evidential considerations counting in favor of having the belief (e.g. Sharadin 2016; Bondy 2018 and forthcoming). As I will try to show, however, most of the cases discussed in the literature can be easily re-described as cases in which a subject believes solely on the basis of evidential reasons. For this reason, I shall concentrate on more recent attempts by Rinard (forthcoming), and especially by McHugh (2013) and McCormick (2015), to vindicate the claim that non-epistemic considerations can enter as reasons in deliberation. However, I shall show that also these attempts are ultimately doomed to fail.

This paper, in particular, is organized as follows. In section 1 , I introduce the view that evidence is normative. In section 2, I explain the strategy alluded at by McHugh to ground the normativity of evidence on the claim that truth is epistemically valuable. Moreover, I describe the variant of McHugh's strategy that is needed, in particular, to vindicate the claim that on counterbalanced evidence in relation to $\mathrm{P}$ one ought to conclude deliberation by suspending judgment about P. In section 3, I motivate the evidentialist claim that epistemic reasons are the sole reasons for believing there are and show that the strategy inspired by McHugh falls afoul of the problem of committing to non-epistemic reasons for believing. In section 4, and subsections, I critically assess the arguments provided by Rinard, McHugh and McCormick to show that non-epistemic considerations can enter as reason in deliberation and explain why they all fail. In section 5, I draw my conclusions.

\section{The Normativity of Evidence}

As is well known, it is very controversial what evidence is. To name just a few debated questions, it is controversial whether a subject's evidence is constituted by mental states of the subject, or by propositions to which a subject is suitably related in virtue of the 
mental states she is in; moreover, it is controversial under what conditions a subject's evidence supports believing a given proposition, and under what conditions a subject can be taken to possess a given piece of evidence. ${ }^{5}$ For the limited purpose of this paper, I want to stay as neutral as possible on all these controversial issues and shall simply assume that a subject $S$ has evidence that a given proposition is true just in case $S$ is aware of an indication of P's truth. This is meant to be compatible with all the available answers to the above-mentioned questions. In the sense just introduced, for instance, I will say that in virtue of having a perceptual experience that $P$ is true $S$ is aware of an indication of P's truth and so has evidence supporting this proposition. By the same token, I'll say that if $S$ is aware that $Q$ can be inferred from $P$, in virtue of justifiably believing $P S$ has an indication of the truth of $Q$, and so has evidence supporting this proposition. I believe that, independently of many important details, we have a notion of evidence on which all this is uncontroversial. What I don't want to stay neutral about is that this notion of evidence has an important normative dimension to it. With this I mean that what evidence one has, and how this evidence relates to any proposition $\mathrm{P}$, has implications for what doxastic attitudes one ought to take toward this proposition if one deliberates about whether to believe it. The view I have in mind can, in particular, be articulated by stating the following three principles.

(Nor1) If $\mathrm{S}$ has evidence that $\mathrm{P}$ is true, $\mathrm{S}$ ought to close deliberation about whether to believe $\mathrm{P}$ by believing $\mathrm{P}$;

(Nor2) If S's evidence doesn't support P over its negation, S ought to close deliberation about whether to believe $\mathrm{P}$ by suspending judgment about $\mathrm{P}$;

\footnotetext{
${ }^{5}$ For a very useful survey of the literature on these issues, see McCain 2014.
} 
(Nor3) If $\mathrm{S}$ has evidence that $\mathrm{P}$ is false, $\mathrm{S}$ ought to close deliberation about whether to believe $\mathrm{P}$ by disbelieving $\mathrm{P}$.

A few clarifications are in order. To say that $S$ deliberates about whether to believe $P$ is to say that $S$ engages in a rational process, structured by the question about whether to believe $\mathrm{P}$, which is closed when $\mathrm{S}$ believes $\mathrm{P}$, disbelieves $\mathrm{P}$ or suspends judgment about $\mathrm{P}$. By saying that $S$ disbelieves $P$ I shall simply mean that $S$ believes the negation of $P$. By saying that $S$ suspends judgment about $P$, however, I won't simply mean that $S$ fails to both believe and disbelieve P. On the account I shall assume of what is involved in suspending judgment about $P$, it is crucial that refraining from both believing and disbelieving $\mathrm{P}$ is the way in which $\mathrm{S}$ concludes her deliberation about whether to believe $\mathrm{P}$. There are thousands of propositions that we fail to both believe and disbelieve simply because we didn't consider them. These, on the account I am assuming, aren't propositions on which we suspend judgment. ${ }^{6} \mathrm{~A}$ final remark about the way the principles above are formulated. They all say that when S's evidence is such and such, S ought to conclude deliberation by doing such and so. This is not to be taken as implying that when one's evidence is such and such one ought to deliberate, and that one ought to conclude deliberation by doing so and so. It is only an abridged form of saying that if one deliberates and one's evidence is such and so, then one ought to conclude it by doing so and so.

\section{Grounding the Normativity of Evidence on the Value of Truth}

\footnotetext{
${ }^{6}$ For instance, many of my readers are probably unconcerned about whether (BA) it is now raining in Buenos Aires. So, whether or not they have evidence one way or another, they simply have no attitude toward BA. To suspend judgment about BA is to do more, it is to refrain from believing and disbelieving BA as a result of having addressed the question about whether to believe it.
} 
Why believe that (Nor1), (Nor2) and (Nor3) are true? In a recent paper, C. McHugh has alluded at a possible strategy to ground these principles on the claim that truth is epistemically valuable (2012: 21). According to McHugh, to carry out this strategy one needs to advert to the following evaluative-to-normative principle schema:

(1) If $A$ is good, and $R$ is a reason to take it that a certain course of action $\varphi$ is conducive to the realization of $A, R$ is a reason to $\varphi$.

Here is how the strategy might proceed. As we have already said, we are assuming that truth is epistemically valuable. The relevant instance of the principle will thus read as follows:

(2) If truth is valuable, and $E$ is a reason to take it that by believing $P$ one would have a true belief, $E$ is a reason for one to believe that $P$.

It is not difficult to see how the latter principle could be used to vindicate (Nor1). Begin to note that:

(3) If $E$ is evidence that $P$ is true, $E$ is a reason to take it that by believing $P$ one would believe a true proposition.

(2) and (3) together entail:

(4) If truth is valuable, and $E$ is evidence that $P$ is true, $E$ is a reason for one to believe P. 
Consider, now, that the following principle seems to express a conceptual truth about the relation between one's evidence/reasons and one's obligations:

(5) If one is faced by a set of alternatives $X, Y \ldots Z$, and one has a reason for selecting $\mathrm{X}$ over $\mathrm{Y} \ldots \mathrm{Z}$, if one is to select one alternative, $\mathrm{X}$ is the alternative one ought to select.

Suppose, to illustrate, that $S$ is faced with the alternative between going out with an umbrella and going out without an umbrella. Suppose further that $S$ has the belief (B) that it is raining outside, and that $S$ doesn't want to get wet. Against the background of the desire not to get wet, $\mathrm{B}$ is a reason for $\mathrm{S}$ for selecting the alternative of going out with an umbrella over the alternative of going out without it; moreover, it seems that in virtue of this fact, going out with an umbrella is the alternative $S$ ought to select if $S$ actually selects one alternative over another (namely, if S doesn't stay at home instead of going out at all). Now apply (5) to the situation in which $S$ is faced with the alternative between believing $P$, disbelieving $\mathrm{P}$ or suspending about $\mathrm{P}$. In this case we have that:

(6) If one is faced with the alternative between believing $\mathrm{P}$, disbelieving $\mathrm{P}$ or suspending about $\mathrm{P}$ and one has a reason to believe $\mathrm{P}$, if one is to select one alternative, believing $\mathrm{P}$ is the alternative one ought to select.

Against the background of (4) and (6), the claim that truth is valuable seems to entail (Nor1). The first principle says that if one has evidence that $\mathrm{P}$ is true, to the extent to which truth is valuable, one has a reason to believe P. So, the claim that truth is valuable entails that evidence that $\mathrm{P}$ is true is a reason for believing $\mathrm{P}$. The second principle says that, in 
this case, if one deliberates about whether to believe $\mathrm{P}$, believing this proposition is the attitude one ought to select. So, (Nor1) seems vindicated.

The same strategy can be easily appealed to in the attempt to vindicate (Nor3). One has simply to adapt the argument above to the case in which one has evidence that $\sim \mathrm{P}$ is true. By so doing, one vindicates the following instance of (Nor1):

$\left(\right.$ Nor $\left.^{*}{ }^{*}\right) \quad$ If $S$ has evidence that $\sim \mathrm{P}$ is true, $\mathrm{S}$ ought to close deliberation about whether to believe $\sim P$ by believing $\sim P$.

$E$ is evidence that $\sim P$ is true if and only if $E$ is evidence that $P$ is false. Moreover, $S$ believes $\sim P$ if and only if $S$ disbelieves $P$. Hence, by replacing one thing for another, $\left(\right.$ Nor $\left.^{*}{ }^{*}\right)$ can be rewritten so as to yield:

(Nor3) If $\mathrm{S}$ has evidence that $P$ is false, $\mathrm{S}$ ought to close deliberation about whether to believe $\mathrm{P}$ by disbelieving $\mathrm{P}$.

It is less clear how the same strategy could be appealed to in the attempt to vindicate (Nor2), which says that if one's evidence doesn't support P over its negation, if one deliberates about whether to believe $\mathrm{P}$ one ought to suspend judgment about $\mathrm{P}$. Remember, to begin with, that to suspend judgment about $\mathrm{P}$ is to conclude deliberation about whether to believe $\mathrm{P}$ by refraining from believing $\mathrm{P}$ and by refraining from disbelieving it. So, the question about whether (Nor2) is true reduces to the question about whether, when one's evidence doesn't support P over its negation, one ought to conclude deliberation about whether to believe $\mathrm{P}$ by refraining from believing $\mathrm{P}$ and by refraining from disbelieving it. On the face of it, the strategy above to vindicate (Nor1) and (Nor3) is unavailable in the case of (Nor2). In accordance with this strategy, whether or not one 
ought to believe (disbelieve) $\mathrm{P}$ if one takes an attitude toward $\mathrm{P}$ depends on whether one has a reason to believe (disbelieve) P. On a principle like (2), whether or not one has a reason to believe (disbelieve) $\mathrm{P}$ in turn is taken to depend on whether one's evidence indicates that by so believing (disbelieving) one would believe a true proposition, thereby promoting the value of truth. But by suspending judgment about $\mathrm{P}$ one could not promote the value of truth, because, differently than believing (disbelieving), to suspend judgment about $P$ is not to take a stand that can be assessed in terms of truth or falsity. Thus, a principle like (2) is immaterial to whether one has a reason to withhold on $\mathrm{P}$ when one's evidence doesn't support P over its negation.

This problem is not avoided by a second principle invoked by McHugh. This principle says that:

(2\#) If something $B$ is bad, and $R$ is a reason to take it that a certain course of action $\varphi$ is conducive to the realization of $B, R$ is a reason not to $\varphi$.

This principle can appear a more promising basis for vindicating (Nor2). For even if by suspending judgment about a proposition $\mathrm{P}$ one could not promote the value of truth, one might thereby prevent an epistemically bad thing from happening—namely believing a false proposition. So, one might suggest, a principle like (2\#) can be employed to determine when one has a reason to suspend judgment about a proposition. This suggestion would however be mistaken. For if $\mathrm{R}$ is a reason to take it that by believing $\mathrm{P}$ one would believe a false proposition, $R$ is a reason to refrain from believing $P$. But at the same time, it is a reason for believing the negation of $\mathrm{P}$, and so is not reason for 
suspending judgment about $\mathrm{P}$; it is a reason for disbelieving $\mathrm{P}^{7}$ Hence, $\mathrm{R}$ could not be a reason for suspending judgment about $P$.

Even if (2\#) is ill suited to the purpose of vindicating (Nor2), it points us in the right direction. The latter principle trades on the idea that there is reason to refrain from doing what one is aware would cause something bad. A different principle, trading essentially on the same idea, says that one has reason to refrain from doing $\varphi$ if one is in no position to rule it out that, by $\varphi$-ing, one would bring about something bad. In particular this second principle says:

(2\#\#) If $B$ is bad, and one has no reason to rule it out that a certain course of action $\varphi$ is conducive to the realization of $B$, one has a reason not to $\varphi$.

To illustrate, suppose that you are about to go out, you don't want to get wet, and you ignore whether it is raining or not. In a similar situation, you seem to have a reason to take the umbrella (namely, to refrain from not taking it). This is so, apparently, because you cannot rule it out that by not taking it you will incur consequences-your getting wet--that are bad for you. The doxastic instance of (2\#\#) is this:

(3\#\#) If having a false belief is bad, and one has no reason to rule it out that by believing $\mathrm{P}$ one would have a false belief, one has a reason not to believe $\mathrm{P}$.

When S's evidence doesn't support P over its negation, one has no reason to rule it out that by believing $\mathrm{P}$ one would believe a false proposition. Thus, it follows that:

\footnotetext{
7 I assume that bivalence holds.
} 
(4\#\#) If having a false belief is bad, and one's evidence doesn't support P over its negation, one has a reason not to believe $\mathrm{P}$.

By a parallel reasoning, one can yield the consequence that:

(5\#\#) If having a false belief is bad, and one's evidence doesn't support P over its negation, one has a reason not to believe $\sim \mathrm{P}$ (namely, not to disbelieve $P$ ).

If one has a reason not to believe $\mathrm{P}$ and one has a reason not to disbelieve $\mathrm{P}$, one has a reason to withhold on $\mathrm{P}$. It hence seems to follow that if one is to take any attitude at all, withholding on $\mathrm{P}$ is the attitude that one ought to take. (Nor2) is thus vindicated.

\section{A problem with the strategy inspired by McHugh}

Even if it might seem initially promising, the strategy to vindicate the normativity of evidence described in the last section soon runs afoul of the following problem. Many authors have stressed (Kelly 2002, Shah 2006, Parfit 2011, Way 2012, Berker 2018) that epistemic reasons are the sole reasons for believing there are. These evidentialist philosophers have argued that epistemic reasons are the sole reasons for believing there are by elaborating on Williams (1973)'s classical theme that one cannot believe at will, namely on the basis of non-epistemic considerations counting in favor of having a given belief. This fact, according to the authors at issue, indicates that these considerations are not reasons for believing, because they cannot play the role that reasons play in deliberation, namely be the considerations on the basis of which one concludes deliberation by believing, disbelieving or by suspending about a proposition.

T. Kelly (2002) has argued that evidential reasons are the sole reasons for believing there are on the ground that evidential reasons are the sole reasons that are capable of 
rationalizing one's beliefs, namely they are the sole kind of reasons on the basis of which one can believe a proposition. This is so, according to Kelly, because it is only one's recognition of epistemic reasons that can play a role of the right sort in the causal history of one's believing that proposition. N. Shah has argued that evidential reasons are the sole reasons for believing there are essentially on the same ground, by contending that evidential reasons are the sole reasons satisfying a general constraint on something being a reason, that Shah calls the deliberative constraint on reasons (2006: 484-5). According to the principle that gives voice to this constraint, roughly, $R$ is a reason to $\varphi$ only if $R$ can dispose one to $\varphi$ in the way characteristic of R's functioning as a premise in one's deliberation as to whether one should $\varphi$. This for Shah is equivalent to the claim that $\mathrm{R}$ disposes one to $\varphi$ through the characteristic motivational force that a consideration exercises as a premise in a deliberative process. So, it entails the claim that $\mathrm{R}$ is capable of being a reason for which an agent $\varphi s$ (Shah 2006: 485). Applied to the case of beliefs, Shah's deliberative constraint on reason commits one to saying that something can be a reason for believing a proposition only if it can be a reason for which one believes that proposition; and according to Shah only evidential reasons satisfy this constraint. This is so, for Shah, because it is a feature of our constitution of cognitive agents that when we deliberate about whether we should believe P, "the question of P's truth hegemonically occupies the focus of our attention", and solely one's epistemic reasons tell for or against the truth of $P$.

It is important not to conflate the claim that Kelly and Shah both accept-that evidential reasons are the sole reasons for believing there are-with a related claim which Kelly and Shah both oppose. This related claim says that evidential reasons are the sole reasons there are for getting oneself to believe a proposition. Something being a reason for believing $\mathrm{P}$ is easily mistaken with something being a reason for getting oneself to believe P. But one thing should not be conflated with another. To illustrate, consider the 
following example. Suppose God tells me that he will destroy the world unless I believe that grass is pink. If Kelly and Shah are right, that God will destroy the world unless I believe that the grass is pink, even if it is a consideration counting in favor of having the belief, is not a reason for believing that grass is pink. For I am unable to believe that grass is pink on the basis of-or for--this reason. Only an epistemic reason could be such a reason. But of course that God will otherwise destroy the world, together with my desire to prevent this from happening, is a reason to undertake any course of action--going to a hypnotist, for instance, or visit an eye surgeon-whose foreseeable consequence is that I end up with the desired belief that grass is pink. With respect to believing that grass is pink, the consideration that God will destroy the world unless I have the belief is motivationally inert, and so does not count as a reason. With respect to acting in a way which is potentially conducive to the acquisition of the belief, however, the same consideration is not motivationally inert, and so can be a reason for acting in the relevant way.

Now that the evidentialist claim that epistemic reasons are the sole reasons for believing there are is on the table, I can move to explain why the strategy inspired by McHugh to ground the normativity of evidence on the value of truth engenders a conflict with it.

The simple reason why (1) engenders a conflict with Kelly's and Shah's claim is that, as everybody is probably willing to concede, a belief can be valuable for nonepistemic reasons. If this is so, the strategy inspired by McHugh can be run to vindicate the existence of non-epistemic reasons in a way which is essentially parallel to the way in which it has been used to vindicate the existence of epistemic reasons (and epistemic prescriptions derived from epistemic reasons).

Suppose, to illustrate the point, that we value loyal beliefs toward a friend. As an example, imagine that a friend of yours is accused of a crime and that there is some (but 
not overwhelming) evidence that your friend committed it. It might be contended that having the belief that your friend is innocent in the teeth of evidence mildly indicating the contrary would be valuable from the point of view of friendship (Keller 2004 endorses this thesis). If this is so, a principle like (1) yields the consequence that you have a friendshiprelated reason to have the belief, even if you don't have an epistemic reason to do so. For you know that forming the belief would be a way to make it the case that more of the value of friendship is instantiated. More in particular, the relevant instance of the principle would say:

(1\#) If having loyal belief toward a friend is valuable, and $E$ is a reason to take it that by coming to believe $\mathrm{P}$ one would thereby form a loyal belief toward a friend, $\mathrm{E}$ is a friendship-related reason for one to believe that $\mathrm{P}$.

Take again an example discussed few lines above, in which God tells me that he is going to destroy the world unless I believe that grass is pink. In a similar situation, my possible belief that grass is pink would be morally and prudentially valuable. So, in that situation (1) would entail that I have a moral and a prudential reason to believe that grass is pink. More in particular:

(1§) If having a belief is morally/prudentially valuable, and $E$ is a reason to take it that by coming to believe P one would thereby form a morally/prudentially valuable belief, $\mathrm{E}$ is a moral/prudential reason for one to believe that $P$.

As is apparent, this schema can be replicated ad abundantiam, yielding the consequence that there are as many kinds of reasons for believing as are the respects under which the value of a belief may be appraised. To resort to Kelly's terminology, when principle (1) is in 
place, the recognition that a consideration $\mathrm{C}$ of kind $\mathrm{X}$ counts in favor of a given belief immediately gives way to the acknowledgment that $C$ rationalizes believing $P$ in the $X$ sense--namely, is a reason of kind $X$ for believing $P$.

To take stock, the following claims form an inconsistent triad:

(a) Beliefs can be valuated practically (morally, prudentially, from the point of view of the value of friendship) as well as epistemically;

(b) If $A$ is valuable, and $R$ is a reason to take it that a certain course of action $\varphi$ is conducive to the realization of $A, R$ is a reason to $\varphi$;

(c) Epistemic reasons are the sole reasons for believing there are.

I think, and I suspect that the majority of my readers will agree, that (a) is uncontroversial. A belief's being held by someone may have consequences of a variety of different sorts, and there is no reason to suppose that these consequences could not be valued for their moral or prudential merits. If I managed to believe that grass is pink, God would refrain from destroying the world, and this seems a morally good consequence that certainly speaks in favor of having the belief. If I managed to believe that my friend is innocent, I would behave as a true friend and this is certainly a good thing, at least from the point of view of the value of friendship, counting in favor of having the belief. So, the inconsistency between (a), (b) and (c) seems to force us to choose between abandoning (b) or (c). In what follows, l'll address some recent strategies that aim to support the view that (c) is the principle we should reject.

\section{Pragmatic Reasons for Believing?}


As it will be remembered, Kelly and Shah pursue essentially the same strategy to vindicate (c). Both start from the premise that $\mathrm{R}$ can be a reason to $\varphi$ only if one could $\varphi$ for, or on the basis of, $\mathrm{R}$; they both then resort to something in the vicinities of Williams' claim that one cannot believe for, or on the basis, of practical reasons, and conclude that there cannot be practical reasons for believing, and that epistemic reasons are the sole reasons for believing there are. One popular strategy to resist Kelly's and Shah's conclusion is based on the attempt to deny Williams' premise by pointing to cases in which one believes for, or on the basis of, a practical reason. All these attempts place themselves in the pragmatist tradition pioneered by James (1897)'s The Will to Believe, and depict situations in which an agent's doxastic deliberation over whether to believe an important proposition cannot be settled on the basis of the available evidence and is allegedly resolved-one way or another-on the basis of practical reasons (Johnston 1995, Sharadin 2016, Bondy 2018 and forthcoming). In one such scenario (Bondy forthcoming), for instance, an agent allegedly manages to believe that moral realism is true-absent decisive argument for or against this philosophical position—solely for the sake of achieving the peace of mind. This and similar cases are unconvincing. I do not doubt for a moment that situations very similar to these happen all the times. In particular, I do not doubt that in many situations one may end up believing $\mathrm{P}$ (or its negation) even if one appreciates that the available evidence is counterbalanced between $P$ and $\sim P$. What I deny is that there are compelling reasons to regard these situations as ones in which one has managed to form a given belief on the basis of one's appreciation of the practical advantages descending from having the belief. All these cases portray situations in which a subject is aware that the available evidence does not favor an alternative (e.g. moral realism) over another (e.g. the negation of moral realism), and in which she is aware of non-epistemic considerations (achieving the peace of mind) counting in favor of having a belief in one of the alternatives (in moral realism). Then, the reader is presented with the intuitive claim that, in the 
circumstances just described, one could end up believing the alternative that is more advantageous from the non-epistemic point of view. From this, since the subject is aware of the fact that the evidence doesn't favor it, it is supposed to follow that she has formed the belief on the basis of the non-epistemic consideration counting in favor of having the belief. But this conclusion simply does not follow from the description of the case. The obvious alternative is that the subject, in spite of being aware of the fact that the available evidence doesn't favor one alternative over another, nonetheless finds herself, to put it in Alston's words, with a "sense that one alternative is more likely than the other" (1987: 266). If this is so, the subject's capacity to form the belief is not explained by the fact that she is responding to the pragmatic considerations favoring the belief of which she is aware, but by the fact that she is spontaneously responding to the appearance of the greater probability of one of the alternatives by believing it. None of the alleged examples of subjects believing $P$ in response to non-epistemic considerations counting in favor of having the belief is described in such a way that this possibility is ruled out on principled grounds. So, I think that the evidentialist who is presented with these cases has always the option of re-describing them as ones in which one manages to form a belief unsupported by the evidence because one has, nonetheless, the appearance that the belief is true. ${ }^{8}$

\subsection{Pragmatic Reasons for Believing: Rinard}

\footnotetext{
${ }^{8}$ At this point, the pragmatist could be credited with the following reply. If the evidence E doesn't favor $\mathrm{P}$ over its negation, it cannot be the case that $S$ has the sense of the greater probability of one alternative over another, say of $\mathrm{P}$, described by Alston. For this sense of the greater probability of $\mathrm{P}$ - which many contemporary epistemologists would call "the seeming that P is true" (see Tucker 2013) — is (some) evidence that $P$ is true. This reply would miss an important point in the evidentialist's reply. The evidentialist maintains that when E doesn't favor $P$ over its negation, and $S$ is aware of practical considerations counting in favor of having the belief that $\mathrm{P}, \mathrm{S}$ can bring herself to believe that $\mathrm{P}$ only if, her appreciation of the evidence notwithstanding, $P$ appears more probable to her. The evidentialist could agree that the sense that $P$ is more probable would be additional evidence that $P$ is true, and simply reformulate her objection by saying that $S$ can bring herself to believe that $P$ only if, her appreciation of the existing evidence notwithstanding, $S$ extends this evidence by coming to have the seeming that $P$.
} 
Rinard (forthcoming) has developed a new challenge to the claim that one cannot believe for, or on the basis of, practical reasons. Differently than the cases discussed above, Rinard's cases are not cases in which one's evidence is counterbalanced between $\mathrm{P}$ and not $\mathrm{P}$, and one nonetheless believes $\mathrm{P}$, or its negation, on the basis of a practical reason. The new cases described by Rinard are cases in which the subject has evidence that the believed proposition is true. However, since the evidence merely causes the belief, and is not the reason for which one believes--since it is not, in Rinard's terminology, the motivating reason for this belief-, they are cases in which the real reason for which one believes can be a practical reason. This, for Rinard, happens when some practical consideration counts in favour of having a belief, and by properly responding to this reason one manages to have some piece of evidence that the belief is true act as a mere cause of it. Here is one of Rinard's examples.

Suppose Arthur is moved by Pascal's wager to appreciate the fact that believing in God would be practically beneficial. Following Pascal's advice, Arthur then seeks the company of religious people, just reads religious books, regularly attends religious ceremonies, and so on and so forth. One day, Arthur's new habits cause in him an intense emotional experience, as a consequence of which Arthur finds himself harbouring the belief that God exists. According to Rinard, the intense emotional experience is (some) evidence that God exists. However, this evidence merely causes Arthur's belief and is not the reason for which Arthur believes that God exists. The reason for which Arthur believes that God exists—Rinard contends—is the practical reason that, by so believing, he will maximize his expected utility.

On the face of it, Rinard's strategy is problematic for at least two reasons. The first problem is one of apparent over-generation. Rinard's strategy presupposes the principle according to which S's inability to do X directly on the basis of the motivating reason $\mathrm{R}$ is no barrier to $S$ 's doing $X$ on the basis of $R$ if there's an action $Y$ such that $S$ is aware that 
by doing $Y$ they will cause $X$, and $S$ can do $Y$ directly on the basis of $R$. To illustrate, she discusses the following non-doxastic example. Suppose I am driving at a high speed and I see a police car. Since I don't want to get a ticket, I now have a reason to slow down; and even if I don't have any direct control over the speed of my car, I can slow down on the basis of my willingness to avoid the ticket by doing something else-by pressing down the brake pedal-that I know will cause the car to reduce its speed. The same is supposed to happen in the doxastic example above. Even if I don't have any direct control over whether I believe that God exist, I can believe that God exist on the basis of my appreciation of the practical benefits of having this belief by doing something else-exposing myself to the psychological influence of evidence that God exist-that I am aware will cause the belief to come into existence. But consider the following example. To ask a hypnotist to incept the belief that $P$ in S's mind (in a possible world in which hypnosis is real) is certainly to do something that one is aware will cause the belief that $\mathrm{P}$ to come into existence. So, suppose $S$ wants the belief that $P$ because it would be practically advantageous to have it, and for this reason goes to a hypnotist asking for treatment. On Rinard's account, the resulting belief would count as held on the basis of her appreciation of the practical advantages descending from having the belief. But, on the face of it at least, a belief induced by hypnosis seems held on no motivating basis at all. So, it is incumbent on Rinard either to explain away the intuition that the hypnosis-induced belief would be sustained by no motivating reason; or to explain why the belief merely caused by the contemplation of evidence would be held on the basis of the relevant non-epistemic reason, while the belief merely caused by the hypnotic treatment would not. A second worry with Rinard's strategy is this. It is crucial, for the success of Rinard's cases, that they involve episodes of believing that are merely caused by the subject's exposure to evidence that $P$, and that these beliefs are held on the basis of the non-epistemic consideration, speaking in favor of having the belief, that has prompted the subject to bring herself under 
to the psychological influence of the evidence in the first place. But all the cases described by Rinard seem to fail a crucial test for the non-epistemic consideration to be the reason on the basis of which the subject entertains the relevant belief, which is the following. If $R$ is the reason on the basis of which $S$ entertains the belief that $P$, in response to the question of why $S$ entertains this belief $S$ is expected to answer by citing $R$. But in the case described by Rinard, intuitively, this is not so. The subject impressed by Pascal's wager, it is natural to suppose, would never mention her practical interest in having the belief if asked for the reason on the basis of which she now believes in God's existence. This reply is easily mistaken with a different reply that Rinard explicitly addresses in her paper. So, before moving forward, it is worthwhile pausing to distinguish my second reply from the different reply addressed by Rinard and explaining why Rinard cannot dismiss my second reply in the same way in which she attempts to dismiss the reply she is explicitly concerned with. According to this different reply, the problem with Rinard's example is not that its protagonist would not cite her practical reason in response to the question why she believes that God exists; rather it is that she would reply that she believes so by citing her religious experience. This, according to the objection addressed by Rinard, would be an indication of the fact that the religious experience is not a mere cause of the belief, but is the motivating reason on the basis of which she has the belief. In response, Rinard correctly observes that the disposition to answer in this way is not necessarily an indication of the fact that the religious experience, above and beyond being the cause of her religious belief, is also the motivating reason on the basis of which the belief is entertained. To begin with, the subject might be disposed to return this answer in response to a why-question merely inquiring into the causal origin of the belief. Moreover, according to Rinard, the motivation to credit the subject with the disposition to reply in this way becomes less compelling when we imagine that the why-question has been disambiguated as one inquiring into the motivating reason for which she does so believe, 
and not merely into its cause This is so, says Rinard, because "we can easily imagine versions of the belief cases in which one would not reply in this way. As pointed out above, it can happen that evidence causes one to have a belief, but one doesn't take that evidence as providing a good reason, or justification, for the belief in question". I am not sure that cases like these are easy to imagine. What I want to point out, however, is independent of the possibility of these cases. So, I can grant that cases like these are possible. The reply I have described above does not rest on the conjecture that the subject of Rinard's example would invariably return the answer that she believes that God exists because of her religious experience. Perhaps there are versions of the case in which she wouldn't. My point is simply that there are no plausible versions of the example in which she would reply by mentioning her practical interest in having the belief, and that this is an indication of the fact that the relevant non-epistemic reason is no motivating reason for it. If there are versions of this case in which the subject would also refrain from indicating the religious experience as the motivating reason why she believes that God exists, say because the experience has merely acted as a cause, I am happy to say that these are versions of the case in which the subject simply happens to have the belief, and in which the belief is held on the basis of no motivating reason at all.

\subsection{Pragmatic Reasons for Believing: McHugh and McCormick}

McHugh (2013) has given a new argument for the claim that non-evidential considerations can enter as reasons in deliberation. Like Rinard, McHugh concedes that one could not believe $\mathrm{P}$ in the absence of (what one takes to be) sufficient evidence that $\mathrm{P}$. According to McHugh, however, we sometimes exert discretion over whether to believe P. While we take it that the available evidence is sufficient to believe $P$, we can withhold on, or we can believe, it. In these cases, non-evidential considerations making one option preferable over another can be part of the reasons on the basis of which we conclude deliberation by 
suspending judgment about (or by believing) the relevant proposition. Here is one of McHugh's cases.

You have a cheque to lodge until Monday morning, it is Friday afternoon, and the bank is overcrowded. It would be much easier for you to go home and return to the bank the following day. In fact, you have a fairly clear memory of having been at the bank on Saturday, and you take this memory adequately to justify the belief that the bank will be open the following day. Ordinarily, you would believe on this basis that the bank will be open. However, given that much depends on the cheque being lodged until Monday morning, you conclude your deliberation by withholding on the proposition that the bank will be open. So, you patiently join the Friday afternoon queue.

Here is another of McHugh's cases.

Your friend is accused of a crime by several seemingly independent witnesses. By your light, this is sufficient evidence to believe that your friend is guilty. All the witnesses might either be mistaken, or they might all be lying, but you think that this possibility is farfetched. By resting on this testimonial evidence, you would ordinarily believe that your friend is guilty. However, according to McHugh, this is a situation in which practical considerations can be part of the reasons on the basis of which you can conclude the deliberation differently. For instance, you can decide to protect your relationship from the damaging effects of believing that your friend is guilty and conclude deliberation by suspending judgment.

McHugh stipulates that in both examples you take the evidence adequately to support the target proposition. In fact, to do the job that these and similar cases are meant to do-namely, support the conclusion that one can deliberate on the basis of nonepistemic considerations--it is crucial that this is so. The reason why can be evinced by inspecting the structure that these cases must exhibit in order to establish their conclusion. The protagonist of these cases must have a given amount of evidence $E$ bearing on a 
proposition P. Moreover, it must be clear that this subject could take it that E adequately supports $\mathrm{P}$ and believe it; and it must be possible for her to take it that $\mathrm{E}$ adequately supports $\mathrm{P}$ and withhold on it. Only at this condition can one look at these cases as cases in which one also deliberates on the basis of non-epistemic considerations. For given that in both cases the subject is aware of epistemic considerations to which she attaches the same epistemic weight—namely the capacity to adequately justify belief-only the hypothesis that non-epistemic considerations have played a role in deliberation can explain why in one case the subject concludes it by withholding on $\mathrm{P}$, and in another the subject concludes it by believing $P$.

In spite of McHugh's explicit stipulation, it is tempting to look at the cases described above in slightly, but crucially different terms. Begin by the first case. You have a fairly clear memory of having been at the bank on Saturday. Were it not for the fact that you badly need your cheque to be lodged until Monday morning, you would ordinarily believe that the bank will be open and spare yourself the torture of joining a long queue. However, you are aware that something really bad will happen if the cheque is not in your bank account by Monday morning. So, you take the possibility of having an inaccurate memory, or of the bank having changed its hours, more seriously, and you conclude your deliberation by suspending judgment on whether the bank will be open. On the face of it, a very plausible explanation of what has happened is this. Ordinarily, when nothing really important hangs on whether your cheque is in your bank account on Monday morning, you would take your memory to adequately support the belief that the bank will be open. However, it is very important that your cheque be there; so you take the possibility of a mistake more seriously, and as a consequence of that you look at the evidence in a different manner, as evidence supporting less adequately the belief that the bank will be open. In light of this assessment of the evidence, you then end up suspending judgment about whether the bank will be open. A similar alternative reading is available also of 
McHugh's second case. Ordinarily, you wouldn't take seriously the possibility that all the witnesses are either lying or mistaken. However, you are aware that they might be all wrong. Given the importance that you attach to not believing that your friend is guilty, you take this possibility into account, and suspend judgment about whether your friend is guilty. A very plausible explanation of what has happened is this. Ordinarily, when nothing really important hangs on whether you believe that some accused person is guilty, you would take the available testimonial evidence to adequately support the belief that the person is guilty. However, it is your friend that is being accused, and believing that he is guilty might seriously harm your relationship. This make you more scrupulous in inspecting the evidence, you take the possibility that all the witnesses are wrong more seriously, and as a consequence of your assessment of the evidence, you suspend judgment about whether your friend is guilty.

On this reading, neither case successfully establishes the conclusion that nonepistemic considerations can play a role in deliberation. In each case, the evidence $\mathrm{E}$ available to a subject has the feature that, depending on the way you set some background parameter having to do with the subject's practical situation, it is psychologically possible for this subject to take it that $E$ adequately supports $P$, and it is psychologically possible for her to take it that it supports $\mathrm{P}$ less adequately. ${ }^{9}$ This being so, these cases can be described as ordinary cases in which one deliberates solely on the basis of epistemic considerations: in the first case, when one concludes the deliberation by believing $\mathrm{P}$, one deliberates on the basis of evidence that one takes adequately to support the proposition; in the second case, when one concludes the deliberation by withholding

\footnotetext{
${ }^{9}$ It deserves emphasis that while McHugh (2013) approvingly quotes from Nickel (2010) about the possibility of cases in which one exerts discretion over whether to withhold on or believe a given proposition, Nickel himself seems to look at these cases differently, as cases in which one has more than one option with respect to the epistemic weight that one attributes to the evidence. By commenting on a case in which one thinks that is very unlikely that a train is passing by, and in which one seems to hear the sound of a locomotive, for instance, Nickel says: "I may take the sound of the locomotive to provide adequate reason to believe that there is a locomotive, or I may take it not to provide adequate reason for that belief. Both responses are reasonable" (2010: 314).
} 
on $\mathrm{P}$, one deliberates on the basis of evidence that one doesn't take to support the proposition sufficiently well. The fact that in both cases the subject deliberates on the basis of the same body of evidence $\mathrm{E}$ may mislead one into believing that the epistemic considerations upon which one deliberates are the same, thereby leaving room for the non-epistemic considerations to make the difference for the way in which the subject concludes her deliberation. But on closer inspection, there is no need to credit the nonepistemic considerations with any role in deliberation. Its different outcomes are more easily explained by a difference in the epistemic considerations available to the subject, by the fact that in one case the subject takes it that the evidence $E$ supports $P$, and in another she takes the same evidence not to support P sufficiently well.

A reader sympathetic with McHugh's case may reply that I have described two plausible variants of McHugh's original cases, and point out that they differ from them precisely because in these cases it has been stipulated that the practical considerations that bring the subject to withhold on the relevant proposition do not affect the subject's assessment of the available evidence. This reply would however misunderstand my point in one important respect. What I am suggesting, in fact, is that we should reject McHugh's assumption that we ever exert discretion over whether to withhold or believe a proposition. We are inclined to think that we possibly exert it only because we have in mind cases in which the practical situation of the subject affects the way in which they appraise the justificatory force of the available evidence. Even if in these cases the subject always responds to purely epistemic considerations, given the way she appraises their justificatory force under the influence of her practical situation, we incline to misdescribe these cases as ones in which the subject either withholds or believes the target proposition by also responding to her practical situation. So, what I am in fact contending is that McHugh's stipulation is illegitimate. 
Before concluding, it deserves mention that McHugh (2013) addresses a worry which is similar to the one I have just described. According to this possible objection, the cases in which we allegedly exert discretion over whether to withhold or believe a proposition, and in which our practical considerations are the reasons for which we end up doing one thing rather than another, are in fact cases in which our practical considerations modify the standards for what counts as sufficient evidence. So, when we allegedly withhold or believe on the basis of our practical considerations it is just that we are appropriately responding to the evidence, given the way in which what counts as an appropriate response varies with the practical considerations we are aware of, and the way in which these tend to lower or raise the prevailing epistemic standards. ${ }^{10}$

It should be noted that the objection under consideration, when compared with the objection I have described above, is premised on a considerably stronger assumption. My suggestion is that the psychological phenomenon described by McHugh as discretion is in fact the different psychological phenomenon whereby the practical considerations we are aware of affect the way in which we appraise the justificatory force of the evidence. ${ }^{11}$ The

\footnotetext{
${ }^{10}$ This possible objection seems to assume a form of contextualism about justification-claims, according to which sentences of the form "S is justified in believing $P$ on the basis of $E$ ", keeping $E$ fixed, are true of false depending on how the epistemic standards are contextually determined in light of S's, or the assertor's, practical interests. A different variant of the same objection could assume a form of pragmatic encroachment about epistemic justification, according to which it is the very fact that $\mathrm{S}$ is or is not justified in believing $\mathrm{P}$ on the basis of E that depends on S's practical interests.

11 The suggestion under consideration bears some similarity to one strand in S. Goldberg (2019)'s rejection of epistemic partiality in friendship. Goldberg argues that the demands of friendship are not inconsistent with the demands of epistemic rationality by suggesting that the value one attaches to friendship generates practical and epistemic reasons - what he calls "value-reflecting reasons"-which make what would otherwise appear partial doxastic practices entirely acceptable from the point of view of ordinary epistemic standards. Goldberg focusses, in particular, on a situation in which A is aware of evidence $E$ indicating that A's friend $S$ is guilty of some terrible deed. The advocate of epistemic partiality in friendship would say that, although epistemic rationality would demand of $A$ that she believe that $S$ is guilty, the demands of A's friendship with $S$ misalign with those of epistemic rationality and require of $S$ a different and more favorable doxastic response. Goldberg rejects this explanation by contending that the value attached by $A$ and $S$ to their friendship generates a series of value-reflecting (practical and epistemic) reasons that make the difference with respect to S's epistemic situation vis-à-vis the proposition that S committed the deed. One such reason is a practical reason to re-open inquiry, which is a practice that may lead $A$ to extend her evidence in such a way that the belief that $S$ is innocent, on A's extended evidence, is epistemically justified. Another is a practical reason to "to see whether or not there are alternative [...] construals of our evidence [...] consistent with belief in our friend's innocence". A similarity between Goldberg's suggestion and the one I have detailed above is that they both rest on the contention that, at least sometimes, one can have different legitimate
} 
objection under discussion says that it is the very justificatory force of the evidence-and not merely our inclination to appraise it one way or another-that depends on the practical considerations we are aware of. This being so, it is however important to register that the answer sketched by McHugh in response to the objection based on the stronger assumption also seems to apply to my objection. So, before moving to the conclusion, it is worthwhile giving to McHugh's response a closer look.

According to McHugh, the alleged fact that the practical considerations one is aware of modify the standards for what counts as sufficient evidence is not enough to show that these considerations do not play the role of reasons in deliberation. Take the first example again. Suppose that the proponent of the objection is right that your interest that the cheque be lodged by Monday morning in your bank account makes it the case that your memory doesn't count as sufficient evidence for believing that the bank will be open, and that you appropriately respond to the evidence by withholding on the proposition that the bank will be open. This, according to McHugh, is still compatible with the claim that your desire not to incur in the bad consequences you expect if the cheque is not there is part of the reasons on the basis of which you withhold on the proposition that the bank will be open tomorrow. Mutatis mutandis, the same objection could be applied to my case. Suppose that I am right that your interest that the cheque be lodged by Monday morning in your bank account makes it the case that you don't think that your memory is sufficient evidence for believing that the bank will be open, and that you appropriately respond to the

\footnotetext{
views on what the same body of evidence justifies, and that both are not committal to the claim that the same evidence may justify more than one attitude. A difference is that while I maintain that the practical (friendship-related) considerations bearing to the accusation against A may psychologically move A to have a different and more favorable view on what the evidence justifies, Goldberg suggests that those practical considerations supply A with a reason to double-check whether such an alternative and more favorable assessment is available. It deserves emphasis, however, that the both of us treat the resulting belief in our friend's innocence as based on purely epistemic reasons. I claim this because I credit the practical considerations with the psychological role of making A alert of different construal of the epistemic bearing of the evidence. Goldberg is clear that it this is so when he maintains that the (friendship)value-reflecting reason to doublecheck for alternative interpretations of the evidence is just an injunction to live up to the epistemic standards of justified belief and responsible belief formation.
} 
way you assess the justificatory force of the evidence by withholding on the proposition that the bank will be open. This, according to McHugh, is still compatible with the claim that the relevant practical considerations are part of the reasons on the basis of which you withhold on the proposition that the bank will be open tomorrow.

I think that McHugh's worry, at least in the way in which it can be used to address my analysis of his cases, can be satisfactorily met. Your awareness that your failing to have the cheque lodged in your bank account by Monday morning would be very bad makes you more attentive to error possibilities that ordinarily you wouldn't take seriously, such as the possibility that your memory might be inaccurate, or that the bank might have changed its hours from your last Saturday visit. Your awareness that your evidence does not rule out those error possibilities determines that you assess its justificatory power accordingly, as evidence insufficient to justify the belief that the bank will be open tomorrow. It could perhaps be said that your awareness of the fact that your evidence does not rule out the error possibilities you are now thinking of is part of the reasons on the basis of which you conclude your deliberation by suspending judgment about the proposition that the bank will be open. Moreover, the fact that you are entertaining the possibility of having an inaccurate memory or that the bank might have changed hours is possibly explained by the fact that you are aware of the practical cost of a mistake. So, there is possibly a sense in which your assessing your evidence in the way you do, and your concluding your deliberation accordingly, is explained by your awareness of the practical stakes. But this is not to say that you assess the evidence the way you do, and that you conclude your deliberation accordingly, for the reason that the practical stakes are high. To believe so is to conflate explanatory reasons-something that can be cited as a cause in the explanation of why an episode of belief formation has occurred-and justifying reasons-the reasons in response to which the belief has been formed. 
A similar ambiguity between explanatory and justificatory reasons seems to afflict McCormick's attempt to show, against Shah, that practical considerations can enter as reasons in deliberation about whether to believe a given proposition (2015: 25-30). McCormick's case turns on the following example, described by Ginet in the attempt to establish the (possibly related) thought that we sometimes manage to decide what to believe. $^{12}$

Sam is a juror in a trial. Sam hears a certain witness reporting something that, if true, would show that the defendant is innocent. Sam is faced with the choice between believing the witness, and then vote to acquit, or believe the persecutor's insinuations that the witness is lying. According to Ginet, in a similar situation it is simply up to Sam to start believing the witness as a result of a decision to do so.

McCormick does not endorse Ginet's reading, according to which Sam can decide to believe the witness. What the example does show, according to her, is that Sam can believe the witness while being aware that he is not doing so for truth-conducive reasons, but for the beneficial consequences that can be expected to derive from having the belief. It shows, for instance, that Sam could believe the witness in response to his recognition that by so doing the trial would come to an end, and he could finally eat some food to calm his hunger.

McCormick's interpretation of the example is open to the reply - that she anticipates-that Sam's awareness of the practical advantages of having the belief can at best act as a cause of the belief, and not as a reason. To act as a reason, so the reply continues, it must be possible for it to function as a premise, but it is plainly impossible for the practical consideration above - that by believing the witness he could finally eat some food--to be

\footnotetext{
12 McCormick does not commit herself to the truth of doxastic voluntarism that Ginet's example is meant to vindicate. Later on in her book, she also illustrates some doubts that examples of this kind might be successful in that respect (2015: 80 ). She limits herself to highlight the features of Ginet's example that, according to her, are germane to the possibly related thought that practical considerations can be part of the reasons we deliberate upon.
} 
a premise from which to conclude that what the witness reports is true. McCormick's attempt to handle the worry at issue is contained in the following quote:

If these considerations [about the beneficial effects of having the belief] can be causes of Sam's belief and Sam can even recognize them as such, it does not seem impossible (or even implausible) for Sam to say I believed the witness because I was fed up and exhausted. This sounds a lot like saying it was at least one of the reasons for his belief.

(2015: 29; the second emphasis is mine)

This passage seems to conflate Sam's acknowledgment, as a sound explanation of his believing the witness, that this belief has been formed under the causal influence of the relevant practical considerations, and these considerations being the reasons in response to which Sam has concluded the deliberation by believing the witness. In other words, it seems to betray the conflation between the explanatory "because"--the kind of because Sam would use in manifesting his realization that the relevant practical considerations causally explain his belief--and the justificatory "because"-which would be more aptly used in manifesting one's awareness that those considerations are the ones in response to which the belief has been formed.

It might be argued, on McCormick's behalf, that what is indicative of the fact that the practical consideration is among the reasons for which he believes the witness is not, as the quote above seems explicitly to suggest, merely his coming to endorse the rationalization according to which he has come to believe the witness because of his urge to eat. Rather, it is Sam's possible failure to relinquish the belief after getting clear about its causal origin that reveals that his belief is now sustained by the relevant pragmatic consideration in the characteristic way in which a reason does sustain belief. The 
suggestion here would be the following: it happens all the times that we form our beliefs under the influence of our practical interests. We may believe that our partner is still willing to stay in a relation, or that we will recover from a harmful illness, because we are unable to face the terrible truth. When we fully realize that this is the case, however, we normally relinquish the relevant belief, because we realize that, while we might have thought otherwise, we really don't have a reason to retain it. If we really realize that our confidence that our partner is not about to leave us stems from our deep emotional attachment to them, or that it is just our fear of death which blinds us from fully acknowledging our medical condition, we abandon the relevant belief (conversely, if we do not abandon them, this is a clear sign that we haven't fully internalized the explanation that we have these beliefs solely because we have a strong practical interest in having them.) So, it might be argued that Sam, to the extent to which he continues to believe the witness after getting clear about its causal origin, must be taking it that, above and beyond causally explaining its existence, it also supplies a reason to maintain the belief. I agree that if Sam retained the belief in the face of his recognition that he formed it under the causal influence of his urge to eat food, this would provide evidence that the belief would be sustained by the urge qua reason. However, I cannot see how it could possibly be true that Sam retained the belief while, at the same time, really appreciating that it is a causal consequence of a practical urge that is totally unrelated to its truth. ${ }^{13}$

\footnotetext{
13 In his review of McCormick's book, J. Bermudez (2016) also identifies in it (and to some extent challenges) the following argument for the contention that practical considerations can be reasons for which we entertain a belief. This argument, according to Bermudez, is premised on McCormick's notion of guidance control over what we believe, which in turn is the notion of control that she takes to be necessary for attributions of doxastic responsibility. According to McCormick, $S$ exercises guidance control over the belief that $P$ provided that the following dual condition is satisfied: (i) the mechanism that produces the belief that $P$ is reasonresponsive, and (ii) it is S's own mechanism, it is one over which S exerts ownership. As an example of when a mechanism satisfies condition (i) and fails to satisfy condition (ii), McCormick invites to think of someone who has been kidnapped and implanted a reason-responsive mechanism. But what does it take exactly for $S$ to exert ownership over a belief-forming mechanism? For McCormick, it involves regarding it as the proper target of reactive attitudes such as blame and praise, or of self-reactive attitudes such as pride, shame or guilt. This in turn involves the disposition to adjust what one believes in a way that is responsive to one's reactive attitudes, or to the reactive attitudes of others, "which are themselves responsive to the belief" (Bermudez 2016: 944). The fundamental feature of this disposition which is key to the argument
} 


\section{Concluding Remarks}

In this paper I think I have accomplished two tasks. I have shown how the strategy inspired by McHugh can be modified so as to vindicate the normativity of evidence, and in particular the principle saying that on counterbalanced evidence in relation to $\mathrm{P}$ one ought, if one deliberates about whether to believe it, to conclude one's deliberation by suspending judgment about P. Then I have motivated the worry that this strategy commits to acknowledging more reasons for believing than we should accept, namely non-epistemic reasons for believing. I have tried to make this worry more pressing by concentrating on the strategies pursued by Rinard, McHugh and McCormick to show that we sometimes base our beliefs on non-epistemic considerations counting in favor of having those beliefs, and by showing why these attempts fail. If I am right, and no better explanation is available of how non-epistemic considerations could enter in deliberation, the strategy inspired by McHugh to ground the Normativity of evidence on the value of truth is hence faced with a serious difficulty. This result, if correct, leaves the philosophers interested in grounding the normativity of evidence on the value of truth with the alternative between finding better arguments to show that non-epistemic reasons for believing are not verboten after all, or, if these arguments are not forthcoming, of devising a different strategy to bridge the value

reconstructed by Bermudez is that it also includes the disposition to adjust our beliefs to non-epistemic reactive attitudes such as blame or guilt. It may centrally include, for instance, the disposition to refrain from believing of one's brother that he stole some money as a response to one's feeling of moral guilt for so believing (McCormick 2015: 114). When one adjusts one's belief in this way, one would not be responding to some epistemic consideration but to one's appreciation of the moral impropriety of one's belief. I don't believe that this argument successfully establishes its conclusion. Take again McCormick's example. The subject's evidence either adequately supports the belief that the brother stole the money, or it doesn't. In the first case, I cannot see how the subject might end up abandoning the belief, no matter how intensely she feels guilty for having the belief, if she remains aware of the evidence and correctly estimates its significance. So, the scenario described in the argument must be one in which the evidence does not adequately support the belief. But in this case, I cannot see how her doxastic output can be seen as a response to non-evidential reasons. For it seems more plausible to say that the subject 's feeling of guilt would act as a motivation for the subject to reassess the epistemic credentials of her belief; and even if it would be out of this motivation that the subject would come to appreciate that her evidence poorly supports the belief, it would be nonetheless solely by responding to these considerations that the subject would come to abandon her belief. 
normative gap. I think we'll have to leave to a different occasion to adjudicate which one is more promising and keep looking with interest at attempts of both kinds.

\section{References}

Alston, W. (1987). The Deontological Conception of Epistemic Justification, Philosophical Perspectives, vol. 2, Epistemology: 257-299.

Berker, S. (2018). A Combinatorial Argument Against Practical Reasons for Belief. Analytic Philosophy, 59, 427-470.

Bermudez, J. (2016). Review of Believing Against the Evidence, by Miriam Schleifer McCormick. Mind, 125 (449): 942-945.

Bondy, P. (2018). Epistemic rationality and epistemic normativity. New York: Routledge

Bondy, P. (forthcoming). The epistemic norm of inference and non-epistemic reasons for belief. Synthese.

Feldman, R. (2000). The Ethics of Belief. Philosophy and Phenomenological Research, 60 (3): 667-695.

Goldberg, S. (2019). Against Epistemic Partiality in Friendship. Philosophical Studies, 176 (8): 2221-2242.

James, W. (1897). The will to believe and other essays in popular philosophy. Cambridge: Harvard University Press.

Johnston, M. (1995). Self-Deception and the Nature of Mind, in C. Macdonald (ed.), Philosophy of Psychology: Debates on Psychological Explanation, Blackwell: 63-91.

Keller S. (2004). Friendship and belief. Philosophical Papers, 33 (3): 329-351

Kelly, T. (2002). The rationality of belief and some other propositional attitudes. Philosophical Studies, $110(2), 163-196$. 
Kvanvig, J. (2003), The Value of Knowledge and the Pursuit of Understanding, Cambridge University Press.

Matheson, D. (2011), How to be an Epistemic Value Pluralist, Dialogue, 50 (2): 391 405.

McCain, K. (2014). Evidentialism and Epistemic Justification, Routledge.

McHugh, C. (2012). The Truth Norm of Belief. Pacific Philosophical Quarterly, 93: 830.

McHugh, C. (2013). The Illusion of Exclusivity. European Journal of Philosophy, 23(4), 1117-1136.

McCormick, M.S. (2015). Believing Against the Evidence. Agency and the Ethics of Belief, Routledge.

Nickel, P. J. (2010). Voluntary Belief on a Reasonable Basis. Philosophy and Phenomenological Research, 81(2), 312-334.

Parfit, D. (2011). On What Matters, Oxford University Press.

Pettigrew, R. (forthcoming). Veritism, Epistemic Risk, and the Swamping Problem, Australasian Journal of Philosophy.

Pritchard, D. (2009). Knowledge, Understanding, and Epistemic Value, Royal Institute of Philosophy Supplement 64:19-43.

Pritchard, D. (2010). Knowledge and Understanding, in Pritchard D., Millar A., Haddock A. (eds.), The Nature and Value of Knowledge: Three Investigations, Oxford University Press.

Pritchard, D. (2011). What is the Swamping Problem?, in A. Reisner and A. SteglichPeterson, Reasons for Belief, Cambridge University Press.

Pritchard, D. (2014). Truth as the Fundamental Epistemic good, in J. Matheson \& Vico R. (eds), The Ethics of Belief, Oxford University Press. 
Reisner, A. (2009). The possibility of pragmatic reasons for belief and the wrong kind of reasons problem. Philosophical Studies, 145(2), 257-272.

Rinard, S. (forthcoming). Believing for Practical Reasons. Nous.

Shah, N. (2006). A new argument for evidentialism. The Philosophical Quarterly., 56 (225), 481-498.

Sharadin, N. (2016). Nothing but the Evidential Considerations?, Australasian Journal of Philosophy, 94 (2): 343-361.

Sylvan K. (2018), Veritism Unswamped, Mind 127 (506): 381-435.

Tucker, C. (ed) (2013). Seemings and Justification. New Essays on Dogmatism and Phenomenal Conservatism, Oxford University Press.

Way, J. (2016). Two Arguments for Evidentialism, The Philosophical Quarterly, 66 (265): 805-818.

Williams, B. (1973). Deciding to Believe, in Williams B., Problems of the Self. Philosophical Papers 1956-1972, Cambridge University Press.

Zagzebski, L. (2000), From Reliabilism to Virtue Epistemology, The Proceedings of the Twentieth World Congress of Philosophy, 5: 173-179.

Zagzebski, L. (2003). The search for the source of the epistemic good. Metaphilosophy, 34: 12-28. 